\title{
Anti-PD-I Monotherapy for Advanced NSCLC Patients with Older Age or Those with Poor Performance Status
}

This article was published in the following Dove Press journal: OncoTargets and Therapy

\section{Taichi Matsubara \\ Takashi Seto \\ Shinkichi Takamori \\ Takatoshi Fujishita \\ Ryo Toyozawa \\ Kensaku Ito \\ Masafumi Yamaguchi (D) \\ Tatsuro Okamoto}

Department of Thoracic Oncology, National Hospital Organization Kyushu Cancer Center, Fukuoka, Japan
Correspondence: Taichi Matsubara Department of Thoracic Oncology, National Hospital Organization Kyushu Cancer Center, 3-I-I, Notame, Minami$\mathrm{Ku}$, Fukuoka, 8II-I395, Japan

Tel +8I-92-54|-323|

Fax +8I-92-55I-4585

Email t_matsu@med.kyushu-u.ac.jp
Purpose: Anti-programmed death 1 (PD-1) antibodies have emerged as frontline treatments for patients with advanced non-small cell lung cancer (NSCLC) on the basis of global Phase III trials. However, current data regarding responses to anti-PD-1 therapy in older patients with NSCLC or those with poor performance status (PS) are limited. Therefore, we examined the therapeutic effect of anti PD-1 antibody in these patients.

Patients: We retrospectively examined consecutive patients treated with anti-PD-1 monotherapy (pembrolizumab or nivolumab) from January 2016 to September 2018.

Results: We enrolled 125 patients (median age, 60 years), $80.8 \%$ of whom were men. Patients aged $\geq 75$ years were considered older patients $(n=15)$, and those with PS $2-3$ were regarded as having poor PS $(\mathrm{n}=11)$. The objective response and disease control rates were $15.4 \%$ and $46.2 \%$, respectively, in older patients and $9.1 \%$ and $27.3 \%$, respectively, in those with poor PS. Progression-free survival (PFS) and overall survival (OS) did not significantly differ between older and younger patients. However, poor PS was significantly associated with poor survival. High programmed death ligand 1 (PD-L1) expression in tumor specimens $(\geq 50 \%)$ was associated with favorable survival in the entire cohort as well as patients with poor PS. Safety analyses demonstrated no significant difference in the occurrence of any adverse event, including grade $\geq 3$ adverse events, between patients with poor PS or older age and the remaining patients.

Conclusion: Anti-PD-1 therapy had similar efficacy in older and younger patients with NSCLC, whereas survival was significantly worse in patients with poor PS. However, immune checkpoint inhibitors may be considered for patients with poor PS harboring positive PD-L1 expression.

Keywords: immunotherapy, non-small cell lung cancer, lung cancer, prognosis

\section{Introduction}

Lung cancer is one of the most fatal malignancies globally, and non-small cell lung cancer accounts for approximately $85 \%$ of all lung cancers. ${ }^{1}$ Chemotherapy has been required to prolong the survival of patients with unresectable or recurrent lung cancer. Over the past decade, the therapeutic management of NSCLC transitioned from conventional therapy to molecular targeted therapy based on the mutation status of oncogenic driver genes such as epidermal growth factor receptor $(E G F R)$ or anaplastic lymphoma kinase. ${ }^{2,3}$ However, the prognosis of patients who do not harbor specific oncogenic gene mutations remained poor even after the discovery of these therapeutic agents. 
Immune checkpoint inhibitors (ICIs), such as programmed death 1/programmed death ligand 1 (PD-1/PDL1) inhibitors, conferred survival advantages compared with standard chemotherapies, and they have become important treatment options for NSCLC. ${ }^{4-6}$ Nivolumab, a monoclonal antibody against PD-1, was first approved for the treatment of patients with metastatic NSCLC who experienced disease progression during or following platinum-based chemotherapy. Subsequently, pembrolizumab, a monoclonal antibody against PD-1, was approved as monotherapy for both NSCLC in the first-line setting and metastatic NSCLC following disease progression during or following platinum-based chemotherapy. Nosaki et al reported that pembrolizumab provided favorable survival outcomes compared with chemotherapy even in elderly patients via a pooled analysis of three prospective clinical trials. ${ }^{7}$ However, the number of older patients ( $\geq 75$ years) was small or unknown, and the performance status (PS) of the enrolled patients was good ( 0 or 1$)$ in these clinical studies.

Although previous retrospective studies have investigated the efficacy or survival benefit of anti-PD-1 therapy in older patients or those with PS $2-4,{ }^{8,9}$ it is important to accumulate more clinical data on these cohorts and identify populations that derive clinical benefit from anti-PD-1 therapy. Thus, we examined the therapeutic benefit and safety profile of PD-1 therapy in older patients or those with poor PS.

\section{Patients and Methods}

\section{Patients}

We retrospectively examined 125 consecutive patients who received anti-PD-1 monotherapy (pembrolizumab or nivolumab) from January 2016 to September 2018 at the Department of Thoracic Oncology, National Hospital Organization Kyushu Cancer Center. These patients were diagnosed with unresectable advanced-stage NSCLC or recurrent disease after curative pulmonary resection. The following clinicopathological characteristics were investigated: age, sex, smoking status, Eastern Cooperative Oncology Group (ECOG) PS, line of treatment, histological type, oncogenic mutation status $(E G F R)$, clinical stage, type of anti PD-1 therapy, and PD-L1 expression in tumor specimens according to immunohistochemistry (monoclonal antibody, 22C3, Dako, Carpinteria, CA, USA). The clinical stage of each patient was defined according to the criteria of the eighth edition of the TNM classification of the International Association for the Study of Lung Cancer. ${ }^{10}$

Patients received nivolumab intravenously at a dose of $3 \mathrm{mg} / \mathrm{kg}$ every 2-3 weeks or pembrolizumab intravenously at a fixed dose of $200 \mathrm{mg}$ every 3-4 weeks in the clinical setting. Treatment continued until disease progression, treatment-related adverse events (trAEs), or death. Treatment response was assessed using the Response Evaluation Criteria in Solid Tumors every 6-10 weeks. ${ }^{11}$ The toxicities of anti-PD-1 therapy were evaluated according to Common Terminology Criteria for Adverse Events version 4.0. TrAEs were defined as all adverse events (AEs) considered associated with ICIs, including immune-related adverse events (irAEs) and non-irAEs. Events caused by other etiologies (infections or other organic diseases) were excluded. ${ }^{12,13}$ Of these AEs, treatment-related pneumonitis was diagnosed on a clinical and radiological basis. Other common causes of pulmonary decompensation, including progression of malignancy, chronic obstructive pulmonary disease, and infection, were excluded. Clinical information and follow-up data were obtained from patients' medical records. Written informed consent was obtained from each patient before inclusion in this study. Our study was conducted in accordance with the Declaration of Helsinki, and was approved by our institutional review board (National Hospital Organization Kyushu Cancer Center, IRB No: 2019-56).

\section{Statistical Analysis}

We performed all statistical analyses using JMP software version 14 (SAS Institute Inc., Cary, NC, USA). Continuous variables were expressed as the mean $\pm \mathrm{SD}$, and categorical variables were expressed as numbers. Differences between two groups for response rate or AEs were assessed using a two-sided Fisher's exact test. The objective response rate (ORR) was defined as the proportion of patients with a partial or complete response to anticancer therapy. The disease control rate (DCR) was a composite of ORR and stable disease. Progression-free survival (PFS) was defined as the time from treatment initiation to the date of disease progression or death. Overall survival (OS) was defined as time from treatment initiation to death from any cause. Hazard ratios (HRs) and 95\% confidence intervals (CIs) were estimated via the Cox proportional hazards model. Multivariate analyses were used to estimate the HRs for independent prognostic values via Cox proportional hazards regression models with the backward elimination method. All factors assessed in the univariate analysis were included 
in the multivariate analysis. $P<0.05$ was regarded as statistically significant.

\section{Results}

\section{Patient Background}

The baseline characteristics of the 125 included patients are presented in Table 1. Of these patients, the median age was 60 years (range, 31-85) years, and 15 patients $(12.0 \%)$ were at least 75 years old (older group). In our cohort, the proportions of patients treated with nivolumab and pembrolizumab were approximately equal. One

Table I Clinical Characteristics of the Enrolled I25 Patients

\begin{tabular}{|c|c|c|}
\hline Factors & & $\begin{array}{l}\text { Number of } \\
\text { Patients }=\mid 25\end{array}$ \\
\hline Age & Median (range) & $60(31-85)$ \\
\hline Sex & $\begin{array}{l}\text { Male } \\
\text { Female }\end{array}$ & $\begin{array}{l}101 \\
24\end{array}$ \\
\hline Smoking status & $\begin{array}{l}\text { Never } \\
\text { Ever }\end{array}$ & $\begin{array}{l}19 \\
106\end{array}$ \\
\hline $\begin{array}{l}\text { Performance status } \\
\text { (PS) }\end{array}$ & $\begin{array}{l}0-1 \\
2-3\end{array}$ & $\begin{array}{l}114 \\
11\end{array}$ \\
\hline Histological type & $\begin{array}{l}\text { Ad } \\
\text { Sq or other type }\end{array}$ & $\begin{array}{l}77 \\
48\end{array}$ \\
\hline EGFR & $\begin{array}{l}\text { Wild-type } \\
\text { Mutant } \\
\text { Unknown }\end{array}$ & $\begin{array}{l}102 \\
10 \\
13\end{array}$ \\
\hline Anti PD-I antibody & $\begin{array}{l}\text { Nivolumab } \\
\text { Pembrolizumab }\end{array}$ & $\begin{array}{l}63 \\
62\end{array}$ \\
\hline Stage & $\begin{array}{l}\text { III or IV } \\
\text { Recurrent after surgery }\end{array}$ & $\begin{array}{l}108 \\
17\end{array}$ \\
\hline Treatment line & $\begin{array}{l}\leq 2 \mathrm{nd} \\
>3 \mathrm{rd}\end{array}$ & $\begin{array}{l}54 \\
71\end{array}$ \\
\hline PD-LI expression & $\begin{array}{l}<1 \% \\
I-49 \% \\
\geq 50 \% \\
\text { Unknown }\end{array}$ & $\begin{array}{l}21 \\
27 \\
45 \\
32\end{array}$ \\
\hline $\begin{array}{l}\text { Treatment after } \\
\text { anti-PD-I therapy }\end{array}$ & $\begin{array}{l}\text { Systemic } \\
\text { Anti-PD-I therapy } \\
\text { Anti-PD-LI therapy } \\
\text { Cytotoxic therapy } \\
\text { Local } \\
\text { BSC (including palliative } \\
\text { radiation therapy) }\end{array}$ & $\begin{array}{l}51 \\
3 \\
1 \\
47 \\
3 \\
71\end{array}$ \\
\hline
\end{tabular}

Abbreviations: EGFR, epidermal growth factor receptor; PD-I, programmed death I; PD-LI, programmed death ligand I; Ad, adenocarcinoma; Sq, squamous cell lung cancer; BSC, best supportive care. hundred fourteen patients had a PS of 0 or 1 (good PS, 71 and 43 patients, respectively), whereas 11 patients had a PS of 2 or 3 (poor PS, 9 and 2 patients, respectively). The major histological type was adenocarcinoma (61.6\%), and 10 patients $(8.0 \%)$ harboring EGFR mutations received anti-PD-1 therapy, and 54 patients received anti-PD-1 therapy in the first- or second-line setting and 71 patients were treated in the third or later lines.

Regarding PD-L1 expression in tumor tissues, 48 patients $(36.8 \%)$ exhibited no or moderate expression (1\%-49\%), and 45 patients had high expression ( $\geq 50 \%)$. The PD-L1 data of 32 patients could not be obtained.

\section{Efficacy}

The median follow-up time was 13.8 months (range, 0.1-43.9 months). In the entire cohort, ORR and DCR were $26.4 \%$ and $49.6 \%$, respectively. As presented in Figure 1, there were no significant differences in the ORR or DCR between older and younger age or good and poor PS (age: $P=0.232$, and $P=0.418$; PS: $P=$ 0.285 , and $P=0.205$, respectively).

Next, we performed survival analyses. As presented in Figure 2, survival did not differ between older and younger patients (PFS, HR $=1.15[95 \% \mathrm{CI}=0.63-2.12]$, $P=0.647$; OS, HR $=1.06[95 \% \mathrm{CI}=0.55-2.06], P=$ 0.858). Contrarily, PFS ( $\mathrm{HR}=2.00$ [95\% CI $=1.00-4.00]$, $P=0.045)$ and $\mathrm{OS}(\mathrm{HR}=2.95[95 \% \mathrm{CI}=1.47-5.94], P=$ 0.0014 ) were significantly worse among patients with poor PS. Furthermore, we performed survival analyses according to tumor PD-L1 expression. In the entire cohort, high PD-L1 expression was associated with better survival (Figure 3A and B). In the poor PS group, positive PD-L1 expression was associated with better survival using cutoff values of both $1 \%$ and $50 \%$ (Figure $3 \mathrm{C}$ and D).

Finally, we performed univariate and multivariate analyses to identify independent prognostic factors. In addition to PS and PD-L1 expression, the occurrence of trAEs and line of therapy were significantly associated with patient survival. In multivariate analysis, poor PS and later line of therapy (3rd-) were independent factors that predicted poor survival (Supplementary Table 1).

\section{Safety}

Table 2 presents anti-PD- 1 trAEs. We compared the incidence of AEs between patients with poor PS or older age and the remaining patients. The rate of trAEs and that of severe trAEs (grade $\geq 3$ ) did not significantly differ when comparing age or PS. Severe pneumonitis was identified in 

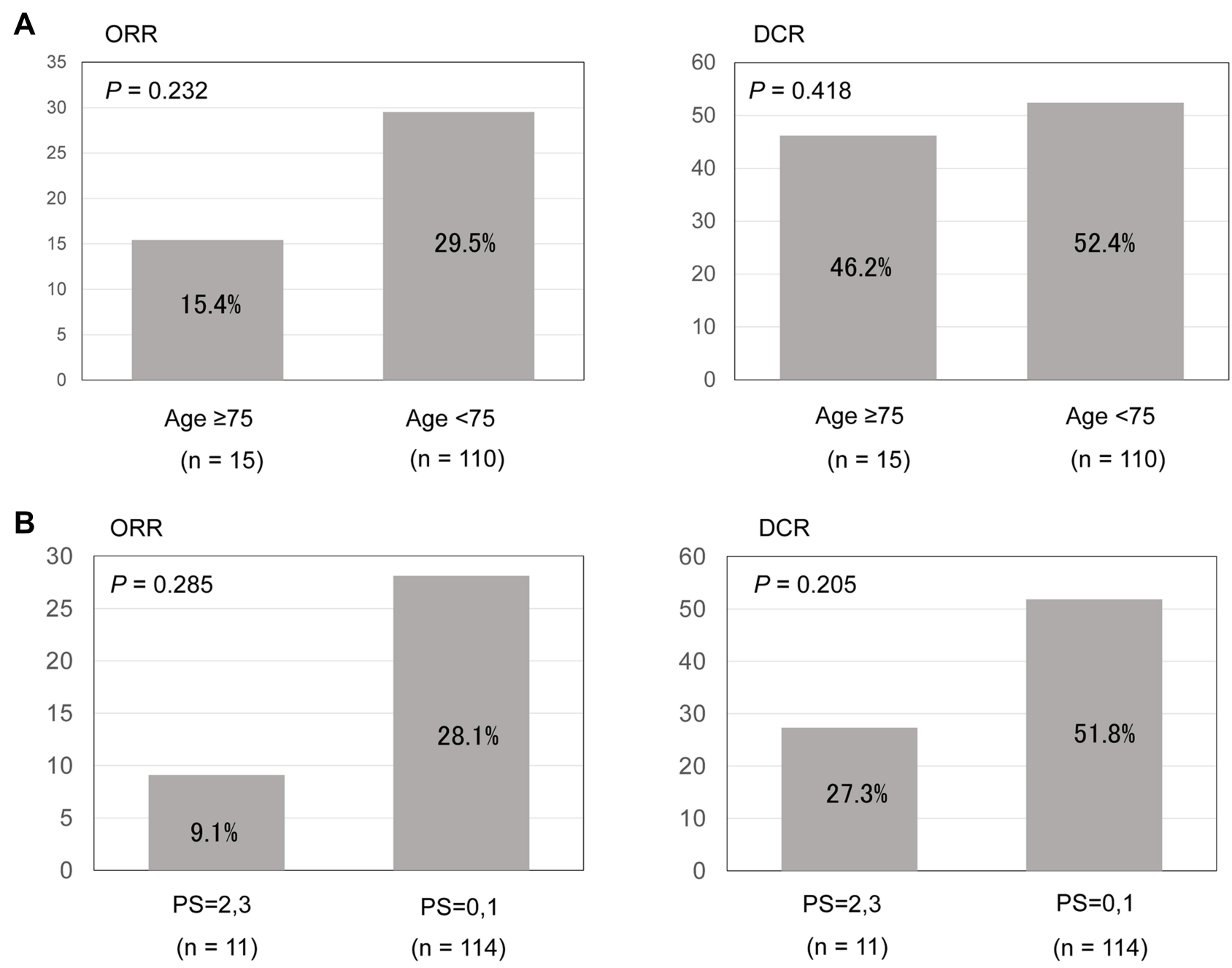

Figure I (A) Therapeutic response in older patients treated with immune checkpoint inhibitors. (B) Therapeutic response in patients with poor performance status treated with immune checkpoint inhibitors.

Abbreviations: ORR, objective response rate; DCR, disease control rate.

three patients $(20.0 \%)$ of older age, and it was more frequent in this group than in the remaining patients $(P=$ 0.0546), although this difference was not statistically significant.

\section{Discussion}

The present study investigated the efficacy and safety of anti-PD-1 therapy in patients with older age and/or poor PS. In this real-world retrospective study, anti-PD-1 therapy provided comparable efficacy in older patients, but survival was worse in patients with poor PS than in their counterparts with good PS. However, positive PD-L1 expression was associated with better survival in poor PS group. Regarding the safety profile, overall all-grade trAE rates did not differ between patients with poor PS or older age and the remaining patients.
Several meta-analyses of clinical trials suggested that the efficacy of anti-PD-1 therapies was similar in older and younger patients. ${ }^{14-16}$ However, the older patients included in these trials were highly selected. In clinical practice, high numbers of older patients require systemic chemotherapy. Thus, it is extremely important to identify the efficacy and safety profiles of ICIs in older patients in the real-world setting. A multicenter retrospective study in Canada and France revealed no relationships between age as a categorical variable $(<60,65,70,75$, and $\geq 75$ years $)$ and survival outcomes. ${ }^{17}$ Furthermore, the study revealed that the rate of immune-related AEs was statistically similar between older ( $\geq 70$ years) and older patients. Corbaux and colleagues investigated survival analyses including 410 patients from three institutions who received ICIs for NSCLC and melanoma. ${ }^{18}$ They performed univariate and 
A

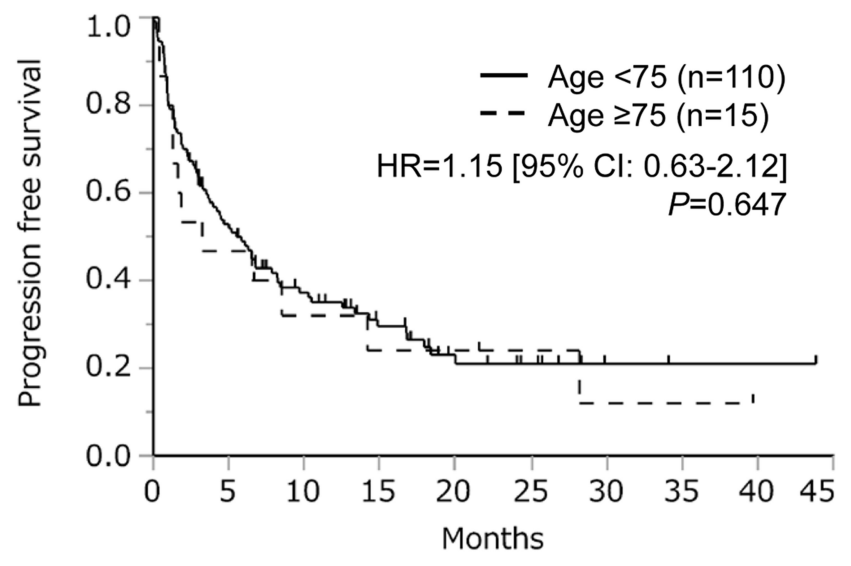

C

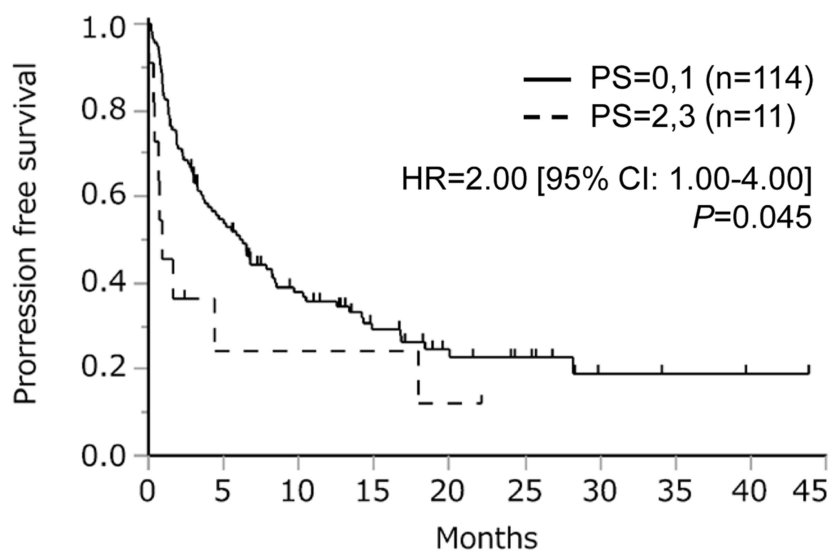

B

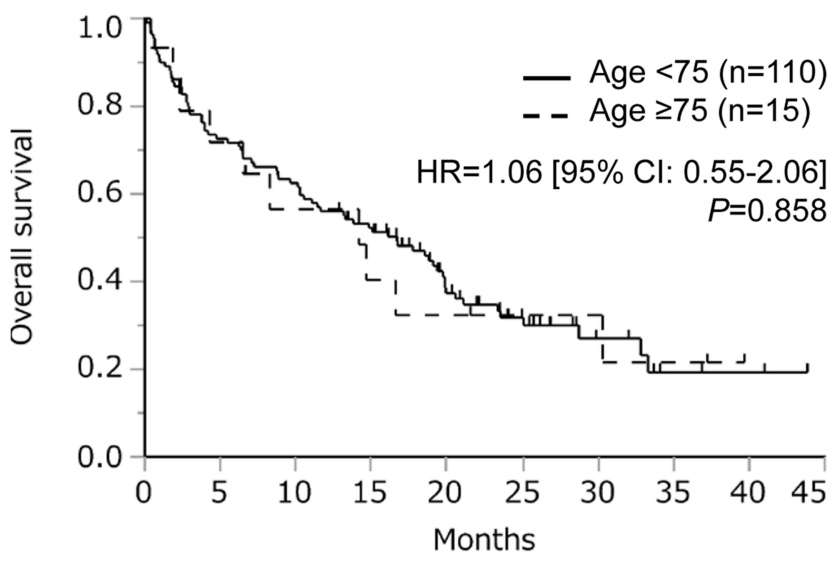

D

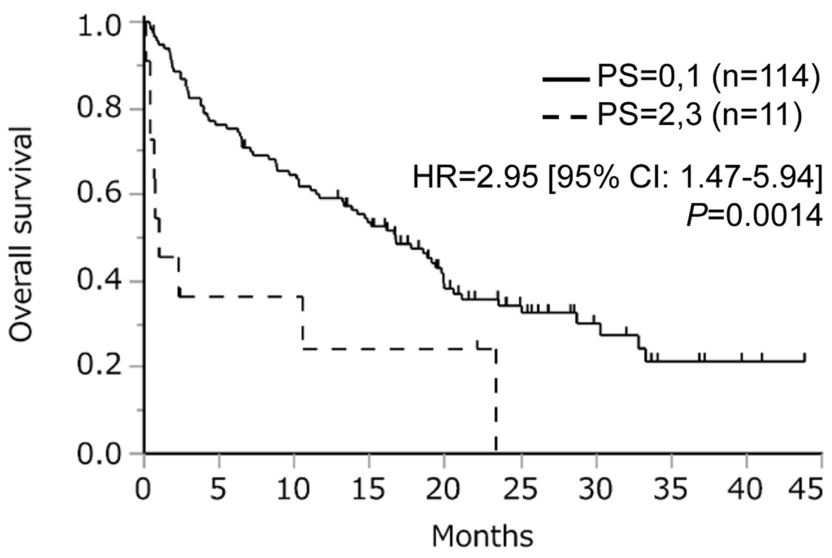

Figure 2 Kaplan-Meier curves for progression-free survival (A) and overall survival (B) among older and younger patients treated with immune checkpoint inhibitors. Kaplan-Meier curves for progression-free survival (C) and overall survival (D) among patients with performance status (PS) 0-I or 2-3.

multivariate analyses to identify the prognostic factors of PFS and OS among patients treated with anti-PD-1 inhibitors and demonstrated that post-treatment survival outcomes did not differ by age. These previous findings are mostly consistent with the results of the present study. Conversely, Lichtenstein et al found that patients older than 80 years had significantly lower OS than their counterparts in a study of 245 patients with NSCLC who were treated with ICIs. ${ }^{19}$ However, this result might have been influenced by the higher proportion of male in the older group. These retrospective and real-world studies provided us insights into the critical management of older patients receiving ICIs.

Furthermore, PS is known as a significant prognostic factor for patients with malignant tumors. Several reports investigated the efficacy and safety of ICIs in patients with poor PS. Our study demonstrated that poor PS was associated with lower ORR and significantly worse survival than good PS. This result was consistent with the findings of several previous studies. Katsura et al compared treatment efficacy by PS status in patients who received nivolumab. ${ }^{20}$ The study found that patients with PS 2-4 (poor PS group) had significantly shorter survival than those with PS 0-1 (good PS group), and survival in the poor PS group was similar to that in patients who received best supportive care (BSC). They also reported that the frequency of severe pneumonitis was significantly higher in the poor PS group than in the good PS group, which was similar to the present study. Naqash et al investigated clinical factors that were associated with survival after nivolumab treatment. ${ }^{21}$ They reported that age was not associated with the PFS and OS, but PS 2-4 was significantly associated with poor survival by multivariate analyses, which is consistent with our results. Furthermore, a meta-analysis of 19 studies that explored the prognostic impact of PS $\geq 2$ on survival in patients NSCLC who 
A

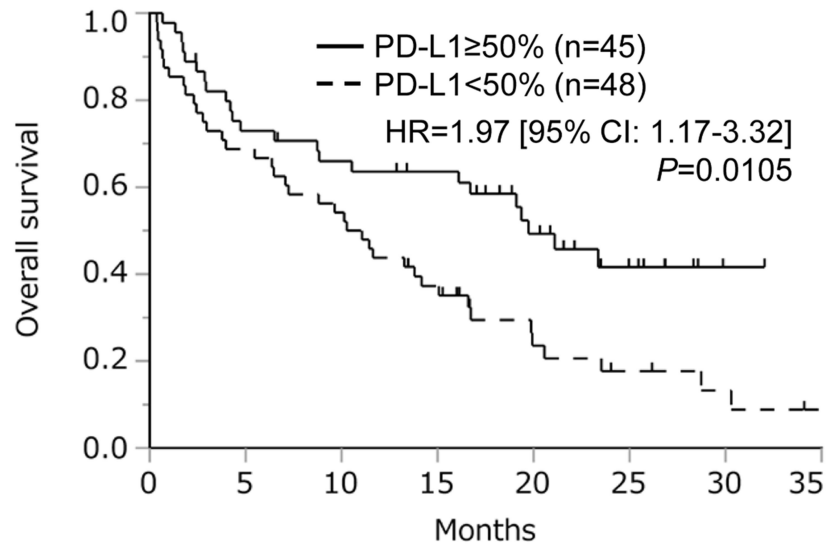

C

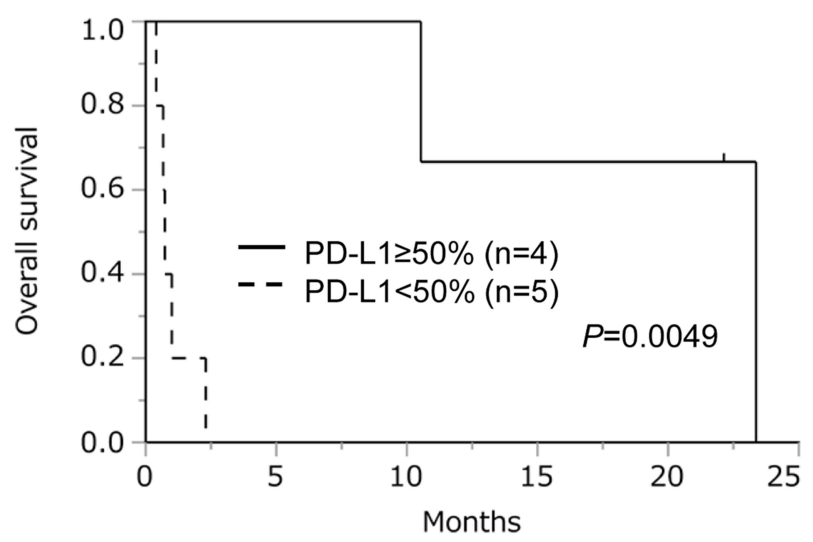

B

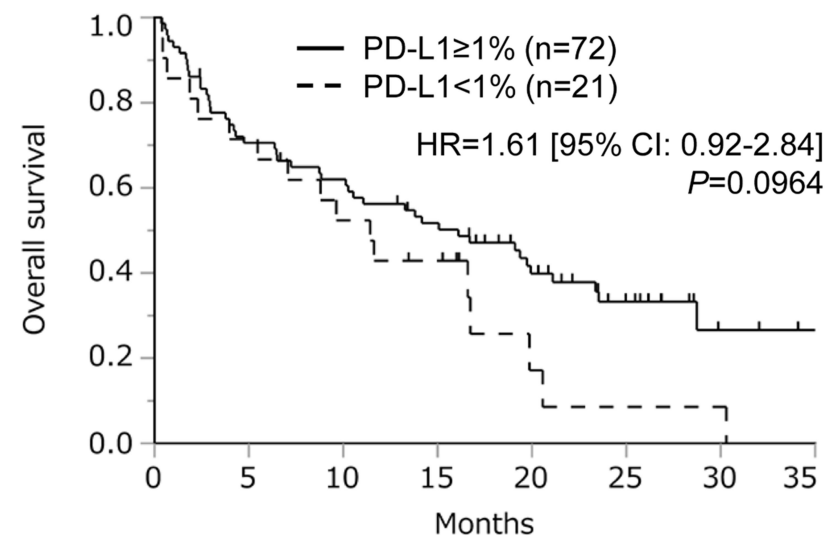

D

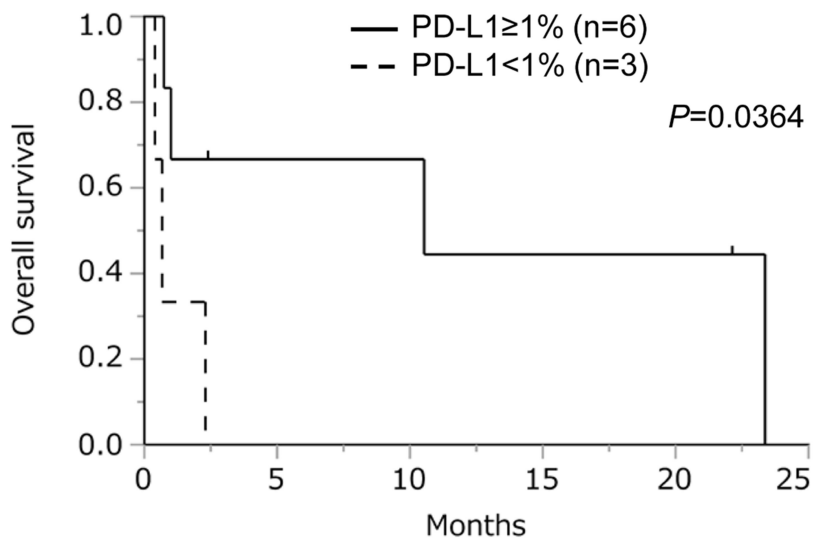

Figure 3 Overall survival following treatment with immune checkpoint inhibitors according to tumor programmed death ligand I (PD-LI) expression (the cut-off values of PD-LI expression were (A) 50\% and (B) I\%, respectively), and subgroup analysis of patients with poor performance status according to tumor PD-LI expression (the cutoff values of PD-LI expression were (C) $50 \%$ and (D) $1 \%$, respectively). Patients lacking PD-LI data were excluded in these analyses.

received ICIs suggested that PS at the start of ICI treatment had prognostic significance, but the predictive value of PS 2 regarding the response to ICIs remained unclear. ${ }^{22}$

These previous reports and the present study suggested that ICI treatment should not be recommended for patients with NSCLC and poor PS, but can we conclude that these patients are truly ineligible for ICI therapy? The results of our prior survival analyses indicated that PD-L1 expression in tumor specimens could be one of the keys for optimizing therapeutic intervention in populations with poor survival. Of note, treatment efficacy was identified even in patients with at least 1\% PD-L1 expression in tumor specimens. PD-L1 expression is known as a predictive biomarker for clinical response to pembrolizumab or nivolumab. ${ }^{23-25}$ Similar to our study, Jodai et al reported that patients with NSCLC and poor PS $(\geq 2)$ and $\geq 50 \%$ PD-L1 expression were expected to benefit from
anti-PD-1/PD-L1 therapy. ${ }^{26}$ Based on these reports, ICI introduction may be considered for patients with positive PD-L1 expression, even if they have poor PS.

Our study had some limitations, including its retrospective, single-institutional nature. In addition, the older and poor PS populations were relatively small, which may have affected the results. Second, our cohort included men and adenocarcinoma patients predominantly. A previous report showed women were more likely to develop irAEs than men, and women with irAEs had significantly longer survival than those without irAEs. Thus, these population biases might have had a strong influence on our results. Finally, the present study did not compare outcomes in patients who received other cytotoxic chemotherapies or BSC. We would like to perform this research in the future to examine the benefits of ICIs in older or poor PS populations. 
Table 2 Treatment-Related Adverse Events Among Patients Aged $\geq 75$ Years or Those with Poor PS

\begin{tabular}{|c|c|c|c|c|c|c|}
\hline \multicolumn{7}{|c|}{ Population } \\
\hline Events & Older $(n=\mid 5)$ & Younger $(n=|| 0)$ & $P$-value & Poor PS $(n=I I)$ & Good PS $(n=1 \mid 4)$ & $P$-value \\
\hline \multicolumn{7}{|l|}{ Any events } \\
\hline All grades & II (73.3\%) & 72 (65.5\%) & 0.7717 & 5 (45.5\%) & 78 (68.4\%) & 0.1794 \\
\hline Grade $\geq 3$ & $5(33.3 \%)$ & $14(12.7 \%)$ & 0.0526 & $2(18.2 \%)$ & 17 (14.9\%) & 0.6736 \\
\hline \multicolumn{7}{|l|}{ Pneumonitis } \\
\hline All grades & $4(26.7 \%)$ & $15(13.6 \%)$ & 0.2430 & $2(18.2 \%)$ & 17 (14.9\%) & 0.6736 \\
\hline Grade $\geq 3$ & $3(20.0 \%)$ & $5(4.6 \%)$ & 0.0546 & I (9.1\%) & 7 (6.1\%) & 0.5321 \\
\hline \multicolumn{7}{|l|}{ Dermatitis } \\
\hline All grades & $3(20.0 \%)$ & $33(30.0 \%)$ & 0.5512 & I (9.1\%) & $35(30.7 \%)$ & 0.1751 \\
\hline Grade $\geq 3$ & $0(0.0 \%)$ & I (0.9\%) & 1.0000 & $0(0.0 \%)$ & I (0.9\%) & 1.0000 \\
\hline \multicolumn{7}{|l|}{ Thyroiditis } \\
\hline All grades & I (6.7\%) & $2(1.8 \%)$ & 0.3208 & $0(0.0 \%)$ & $3(2.6 \%)$ & 1.0000 \\
\hline Grade $\geq 3$ & $0(0.0 \%)$ & $0(0.0 \%)$ & 1.0000 & $0(0.0 \%)$ & $0(0.0 \%)$ & 1.0000 \\
\hline \multicolumn{7}{|l|}{ Colitis } \\
\hline All grades & $2(13.3 \%)$ & $6(5.5 \%)$ & 0.2458 & $0(0.0 \%)$ & $8(7.0 \%)$ & 1.0000 \\
\hline Grade $\geq 3$ & $0(0.0 \%)$ & $2(1.8 \%)$ & 1.0000 & $0(0.0 \%)$ & $2(1.8 \%)$ & 1.0000 \\
\hline \multicolumn{7}{|l|}{ Hepatitis } \\
\hline All grades & $0(0.0 \%)$ & 5 (4.6\%) & 1.0000 & $0(0.0 \%)$ & $5(4.4 \%)$ & 1.0000 \\
\hline Grade $\geq 3$ & $0(0.0 \%)$ & I (0.9\%) & 1.0000 & $0(0.0 \%)$ & I (0.9\%) & 1.0000 \\
\hline \multicolumn{7}{|l|}{ Adrenal failure } \\
\hline All grades & $0(0.0 \%)$ & $3(2.7)$ & 1.0000 & $0(0.0 \%)$ & $3(2.6 \%)$ & 1.0000 \\
\hline Grade $\geq 3$ & $0(0.0 \%)$ & I (0.9\%) & 1.0000 & $0(0.0 \%)$ & I (0.9\%) & 1.0000 \\
\hline \multicolumn{7}{|l|}{ Others $^{\mathrm{a}}$} \\
\hline All grades & $6(40.0 \%)$ & 37 (33.6\%) & 0.7728 & $4(36.4 \%)$ & 39 (34.2\%) & 1.0000 \\
\hline Grade $\geq 3$ & $2(13.3 \%)$ & $6(5.5 \%)$ & 0.2458 & I (9.1\%) & 7 (6.1\%) & 0.5321 \\
\hline
\end{tabular}

Note: ${ }^{a}$ Others: fatigue, fever, embolism, anorexia, pericarditis, mucositis, nausea, myalgia, arthralgia, and any outliers of laboratory test.

Abbreviation: PS, performance status.

In conclusion, although age was not predictive of survival following ICI therapy in patients with NSCLC, patients with poor PS had a worse prognosis than those with good PS. However, it may be worth considering ICIs for patients with positive PD-L1 expression, even those with poor PS.

\section{Acknowledgment}

We thank Joe Barber Jr., PhD, from Edanz Group for editing a draft of this manuscript.

\section{Funding}

This research did not receive grants from funding agencies.

\section{Disclosure}

The authors declare no conflicts of interest.

\section{References}

1. Bray F, Ferlay J, Soerjomataram I, Siegel RL, Torre LA, Jemal A. Global cancer statistics 2018: GLOBOCAN estimates of incidence and mortality worldwide for 36 cancers in 185 countries. CA Cancer J Clin. 2018;68(6):394-424. doi:10.3322/caac.21492

2. Hida T, Nokihara H, Kondo M, et al. Alectinib versus crizotinib in patients with ALK-positive non-small-cell lung cancer (J-ALEX): an open-label, randomised Phase 3 trial. Lancet. 2017;390(10089):29-39. doi:10.1016/S0140-6736(17)30565-2

3. Soria JC, Ohe Y, Vansteenkiste J, et al. Osimertinib in untreated EGFR-mutated advanced non-small-cell lung cancer. $N$ Engl J Med. 2018;378(2):113-125. doi:10.1056/NEJMoa1713137

4. Brahmer J, Reckamp KL, Baas $P$, et al. Nivolumab versus docetaxel in advanced squamous-cell non-small-cell lung cancer. $N$ Engl $J$ Med. 2015;373(2):123-135. doi:10.1056/NEJMoa1504627

5. Reck M, Rodriguez-Abreu D, Robinson AG, et al. Pembrolizumab versus chemotherapy for PD-L1-positive non-small-cell lung cancer. $N$ Engl J Med. 2016;375(19):1823-1833. doi:10.1056/NEJMoa1606774

6. Rittmeyer A, Barlesi F, Waterkamp D, et al. Atezolizumab versus docetaxel in patients with previously treated non-small-cell lung cancer (OAK): a phase 3, open-label, multicentre randomised controlled trial. Lancet. 2017;389(10066):255-265. doi:10.1016/S0140-6736(16)32517-X 
7. Nosaki K, Saka H, Hosomi Y, et al. Safety and efficacy of pembrolizumab monotherapy in elderly patients with PD-L1positive advanced non-small-cell lung cancer: pooled analysis from the KEYNOTE-010, KEYNOTE-024, and KEYNOTE-042 studies. Lung Cancer. 2019;135:188-195. doi:10.1016/j.lungcan. 2019.07.004

8. Duma N, Abdel-Ghani A, Yadav S, et al. Sex differences in tolerability to anti-programmed cell death protein 1 therapy in patients with metastatic melanoma and non-small cell lung cancer: are we all equal? Oncologist. 2019;24(11):e1148-e1155. doi:10.1634/theoncologist.2019-0094

9. Arias Ron D, Areses Manrique MC, Mosquera Martínez J, et al. Efficacy and safety of Nivolumab in older patients with pretreated lung cancer: a subgroup analysis of the Galician lung cancer group. J Geriatr Oncol. 2020. doi:10.1016/j.jgo.2020.11.010

10. Nicholson AG, Chansky K, Crowley J, et al. The international association for the study of lung cancer lung cancer staging project: proposals for the revision of the clinical and pathologic staging of small cell lung cancer in the forthcoming eighth edition of the TNM classification for lung cancer. $J$ Thorac Oncol. 2016;11(3):300-311. doi:10.1016/j.jtho.2015.10.008

11. Schwartz LH, Litière S, de Vries E, et al. RECIST 1.1-update and clarification: from the RECIST committee. Eur $J$ Cancer. 2016;62:132-137. doi:10.1016/j.ejca.2016.03.081

12. Li L, Li G, Rao B, et al. Landscape of immune checkpoint inhibitor-related adverse events in Chinese population. Sci Rep. 2020;10(1):15567. doi:10.1038/s41598-020-72649-5

13. Shankar B, Zhang J, Naqash AR, et al. Multisystem immune-related adverse events associated with immune checkpoint inhibitors for treatment of non-small cell lung cancer. JAMA oncol. 2020;6 (12):1952-1956. doi:10.1001/jamaoncol.2020.5012

14. Nishijima TF, Muss HB, Shachar SS, Moschos SJ. Comparison of efficacy of immune checkpoint inhibitors (ICIs) between younger and older patients: a systematic review and meta-analysis. Cancer Treat Rev. 2016;45:30-37. doi:10.1016/j.ctrv.2016.02.006

15. Elias R, Giobbie-Hurder A, McCleary NJ, Ott P, Hodi FS, Rahma O. Efficacy of PD-1 \& PD-L1 inhibitors in older adults: a meta-analysis. J Immunother Cancer. 2018;6(1):26. doi:10.1186/ s40425-018-0336-8

16. Wu Y, Ju Q, Qian B, Zhang F, Shi H. The effectiveness of PD-1 inhibitors in non-small cell lung cancer (NSCLC) patients of different ages. Oncotarget. 2018;9(8):7942-7948. doi:10.18632/oncotarget.23 678
17. Elkrief A, Richard C, Malo J, et al. Efficacy of immune checkpoint inhibitors in older patients with non-small cell lung cancer: real-world data from multicentric cohorts in Canada and France. J Geriatr Oncol. 2020;11(5):802-806. doi:10.1016/j.jgo.2020.01.002

18. Corbaux P, Maillet D, Boespflug A, et al. Older and younger patients treated with immune checkpoint inhibitors have similar outcomes in real-life setting. Eur J Cancer. 2019;121:192-201. doi:10.1016/j. ejca.2019.08.027

19. Lichtenstein MRL, Nipp RD, Muzikansky A, et al. Impact of age on outcomes with immunotherapy in patients with non-small cell lung cancer. $J$ Thorac Oncol. 2019;14(3):547-552. doi:10.1016/j.jtho.20 18.11.011

20. Katsura H, Suga Y, Araya T, et al. Efficacy and safety of nivolumab in patients with advanced non-small-cell lung cancer and poor performance status. J Cancer. 2019;10(10):2139-2144. doi:10.7150/jca.31217

21. Naqash AR, Ricciuti B, Owen DH, et al. Outcomes associated with immune-related adverse events in metastatic non-small cell lung cancer treated with nivolumab: a pooled exploratory analysis from a global cohort. Cancer Immunol Immunother. 2020;69(7):117 7-1187. doi:10.1007/s00262-020-02536-5

22. Dall'Olio FG, Maggio I, Massucci M, Mollica V, Fragomeno B, Ardizzoni A. ECOG performance status $\geq 2$ as a prognostic factor in patients with advanced non small cell lung cancer treated with immune checkpoint inhibitors-a systematic review and metaanalysis of real world data. Lung Cancer. 2020;145:95-104. doi:10.1016/j.lungcan.2020.04.027

23. Gibney GT, Weiner LM, Atkins MB. Predictive biomarkers for checkpoint inhibitor-based immunotherapy. Lancet Oncol. 2016;17 (12):e542-e551). doi:10.1016/S1470-2045(16)30406-5

24. Sacher AG, Gandhi L. Biomarkers for the clinical use of PD-1/PD-L1 inhibitors in non-small-cell lung cancer: a review. JAMA oncol. 2016;2(9):1217-1222. doi:10.1001/jamaoncol.2016.0639

25. Reck M, Rodríguez-Abreu D, Robinson AG, et al. Updated analysis of KEYNOTE-024: pembrolizumab versus platinum-based chemotherapy for advanced non-small-cell lung cancer with PD-L1 tumor proportion score of $50 \%$ or greater. J Clin Oncol. 2019;37 (7):537-546. doi:10.1200/JCO.18.00149

26. Jodai T, Saruwatari K, Ikeda T, et al. Clinical outcomes and predictive value of programmed cell death-ligand 1 expression in response to anti-programmed cell death 1/ligand 1 antibodies in non-small cell lung cancer patients with performance status 2 or greater. Int J Clin Oncol. 2021;26(1):78-86. doi:10.1007/s10147-020-01789-5

\section{Publish your work in this journal}

OncoTargets and Therapy is an international, peer-reviewed, open access journal focusing on the pathological basis of all cancers, potential targets for therapy and treatment protocols employed to improve the management of cancer patients. The journal also focuses on the impact of management programs and new therapeutic agents and protocols on patient perspectives such as quality of life, adherence and satisfaction. The manuscript management system is completely online and includes a very quick and fair peer-review system, which is all easy to use. Visit http://www.dovepress.com/ testimonials.php to read real quotes from published authors. 